\title{
Giant parovarian cyst: A case report
}

\section{Dev parovaryan kist: Olgu sunumu}

\author{
Volkan Sarper ERIKCI, Demet PAYZA, Münevver HOŞGÖR \\ Dr. Behçet Uz Çocuk Hastalıkları ve Cerrahisi Ĕ̆itim ve Araştırma Hastanesi, Çocuk Cerrahisi Kliniğ̈i, İzmir
}

Giant parovarian cysts in adolescents are rare clinical entities ${ }^{(1-2)}$. They usually arise from the broad ligament predominantly from mesothelium covering the peritoneum but may also be observed in between the fallopian tube and ovary. Although they are usually asymptomatic, symptoms due to pressure effect to neighbourhood organs or symptoms due to complications such as enlargement, torsion, perforation and hemorrhage may also be observed. Conservative ovarian surgery including enucleation of the cyst with preservation of the ovary and fallopian tubes is the standard therapy for the development of puberty and future fertility ${ }^{(3,4)}$. In complicated cases excision of ovary and/or fallopian tubes may also be needed. We present a case of giant paraovarian cyst in an 14-year-old girl treated by enucleation of the cyst with preservation of the ovary and review of the literature on this subject.

A 14-year-old girl was admitted to our department due to a 1 month-old huge abdominal cystic mass extending from the symphysis pubis to the epigastric region. She was medically treated for precocious puberty for 4 years. Clinical examination revealed a manifest bulge of the entire abdomen.Ultrasonography and computed tomography (CT) of the abdomen and pelvis revealed a huge unilocular smooth surface cyst without septations filling the entire abdominal cavity (Figure 1). Maximum diameter of the cyst was 40 $\mathrm{cm}$. Due to pressure effect of the cystic mass, cranial displacement of the liver, posterior relocation of the intestine with right ureteral dilatation was observed.
Laboratory test results were within normal limits, including the LDH, $\beta$-HCG, AFP, and CA-125. Clinical investigations and radiological work-up excluded any signs of malignancy. Regarding the risk of cyst rupture and limited space within the abdomen, laparoscopic approach was found to be difficult and the patient underwent elective surgery with laparatomy. Intraoperatively, there was a huge paraovarian cyst measuring $40 \times 27 \times 19 \mathrm{~cm}$ with a fluid volume of 14 liters extending to the left fallopian tube and left ovary (Figure 2). The right ovary and fallopian tube were found to be normal. Due to close proximity to the left fallopian tube, the giant cyst was excised together with the left fallopian tube and the left ovary was preserved. Histopathology revealed serous cystadenoma with no solid components. With a follow-up period of 3 years, the postoperative course was eventless and the patient was well.

Paraovarian cysts are uncommon in children and account for $10 \%$ to $33 \%$ of adnexal masses and are most commonly seen in the $3 \mathrm{rd}$ and the $4^{\text {th }}$ decades of life ${ }^{(5,6)}$. They vary from small asymptomatic lesions to larger cysts. Enlarged cysts become symptomatic due to mass effect including abdominal pain and distension. In addition to precocious puberty, our patient presented with a huge abdominal bulge producing abdominal discomfort which necessitated surgical intervention. If cysts extending into the layers of the broad ligament do not have pedicles, complications related to paraovarian cysts have been rarely reported. These complications include torsion, hemorrhage, 
perforation and neoplasm within the cyst ${ }^{(5)}$. These masses are usually seen during puberty but may arise as a neonatal intraabdominal mass ${ }^{(4)}$. Our adolescent patient presented with a huge abdominal mass.

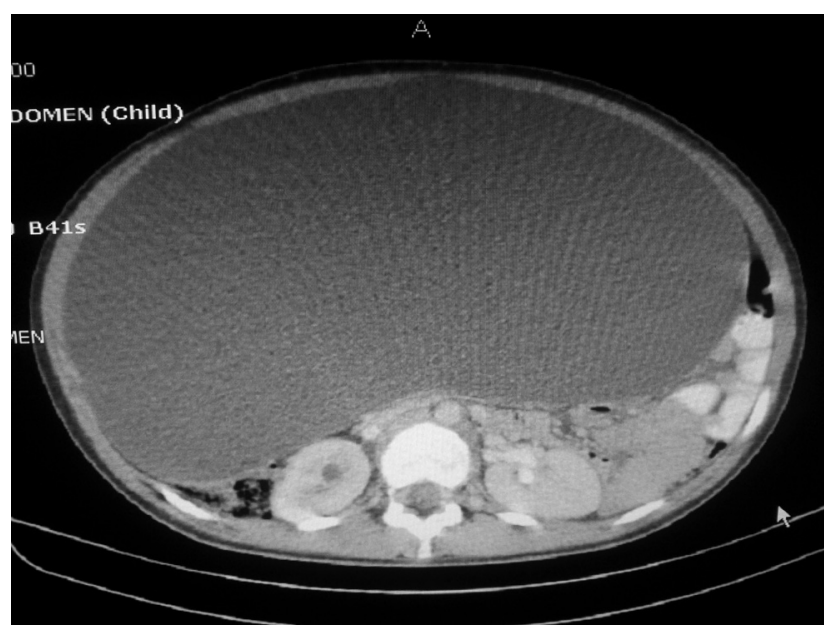

Figure 1. Computed tomography scan showing giant cystic lesion filling the entire abdominal cavity.

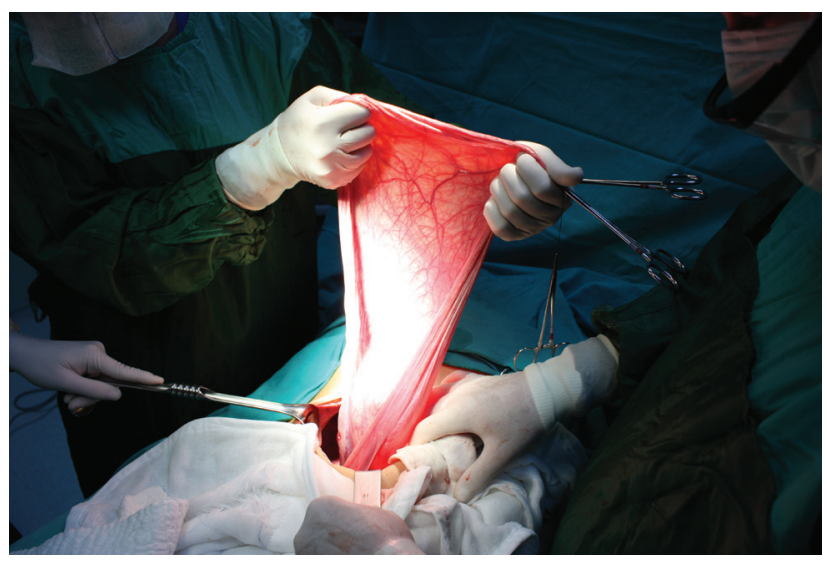

Figure 2. Operative view of the case. Note the cyst was pulled out of the abdominal cavity and cyst content was evacuated.

Although ovarian cysts are labelled as large cyts when they are over $5 \mathrm{~cm}$ and giant when they are over $15 \mathrm{~cm}$, giant paraovarian cysts lack a strict numerical definition and there are no uniformly accepted criteria that define this entity ${ }^{(8)}$. Although cysts that reach such a giant size are almost always benign, careful diagnostic work-up including imaging and analysis of tumor markers with a oncology consultation should be carried out in suspect cases with malignancy. In case of malignancy, open surgical intervention is highly recommended. In our patient laboratory work-up was normal, including analysis of oncological markers LDH, $\beta$-HCG, AFP, and CA-125. Clinical investigation and radiological tests including oncological consultation excluded any signs of malignancy.Giant paraovarian cysts always require resection because of symptoms due to mass effect the cyst produces, difficulties in establishing the origin of the mass, possible complications including torsion, hemorrhage, perforation and a risk of malignancy ${ }^{(5)}$. Enucleation of the paraovarian cyst with an attempt of ovarian salvage should be considered. In our case, due to close proximity to the left fallopian tube, the giant cyst was excised together with the left fallopian tube and the left ovary was preserved. This procedure can be performed by laparoscopy or by an open surgical intervention. Presently laparoscopy is widely used in pediatric surgery with the advantages of minimal invasive technique including better cosmesis, less pain and shorter hospital stay. Regarding the risk of cyst rupture and limited working space, the laparoscopic approach was found to be infeasible in our patient and an open surgical intervention was performed. The histology of paraovarian cysts has been described well and papillary serous cystadenoma, borderline tumor and endometrial sarcoma arising paraovarian cysts have all been reported ${ }^{(6)}$. Histopathological examination revealed serous cystadenoma with no solid components in our patient.

Preoperative diagnosis of paraovarian cyst is difficult and it should be included in the differential diagnosis of abdomino-pelvic masses. As is commonly advocated for ovarian salvage in adnexal torsions, preservation of the ovary during the surgical intervention -if possible- may increase the future reproductive potential of these patients.

\section{REFERENCES}

1. Ateş O, Karakaya E, Hakgüder G, Olguner M, Seçil M, Akgur FM. Laparoscopic excision of a giant ovarian cyst after ultrasound-guided drainage. J Ped Surg 2006;41:E9-E11. http://dx.doi.org/10.1016/j.jpedsurg.2006.06.023

2. Sri Paran T, Mortell A, Devaney D, Pinter A, Puri P. Mucinous cystoadenoma of the ovary in perimenarchal girls. 
Pediatr Surg Int 2007;22:224-7.

http://dx.doi.org/10.1007/s00383-005-1624-1

3. Comerci JT, Licciardi F, Bergh PA, Gregori C, Breen J. Mature cystic teratoma: A clinic-pathological evaluation of 517 cases and review of the literature. Obstet Gynecol 1994:84:22-8.

4. Koc E, Türkyılmaz C, Atalay Y, Basaklar C, Bideci A. Neonatal ovarian cyst associated with intestinal obstruction. Indian J Pediatr 1997;64:555-7. http://dx.doi.org/10.1007/BF02737767

5. Okada T, Yoshida H, Matsunaga T, Kouchi K, Ohtsuka Y, Takanao H, Horie H, Ohnuma N. Paraovarian cyst with torsion in children. J Pediatr Surg 2002;37:937-40. http://dx.doi.org/10.1053/jpsu.2002.32922

6. Macarthu M, Mahomed AA. Laparoscopy in the diagnosis and management of a complicated paraovarian cyst. Surg Endosc 2003;17(10):1676-7. http://dx.doi.org/10.1007/s00464-003-4211-3

7. Sagili H, Krishnan M, Dasari P. Huge bilateral paramesonephric cysts in a 25 year old nulliparous woman. $J$ Clin Diagnostic Research 2013;7(11):2580-90. http://dx.doi.org/10.7860/jcdr/2013/6563.3597

8. Dolan MS, Boulanger SC, Salameh JR. Laparoscopic management of giant ovarian cyst. JSLS 2006;10:254-6.

9. Vlahakis-Millaras E, Millaras D, Koutsoumis G, Miliaras S, Spyridakis I, Papadopoulos MS. Paratubal cysts in young females as an incidental finding in laparotomies performed for right lower quadrant abdomianal pain. Pediatr Surg Int 1998;13:141-2. http://dx.doi.org/10.1007/s003830050268

10. Honore LH, O'Hara KE. Serous papillary neoplasms arising in paramesonephric parovarian cysts. A report of eight cases. Acta Obstet Gynecol Scand 1980;59(6):525-8. http://dx.doi.org/10.3109/00016348009155444

11. Puig F, Crespo R, Marquina I. Serous cystadenoma of borderline malignancy arising in a parovarian paramesonephric cyst. Eur J Gynaecol Oncol 2006;27(4):417-8.

12. Persaud V, Anderson MF. Endometrial stromal sarcoma of the broad ligament arising in an area of endometriosis in a paramesonephric cyst. Case report. Br J Obstet Gynaecol 1977;84(2):149-52. http://dx.doi.org/10.1111/j.1471-0528.1977.tb12544.x

13. Kiseli M, Çağlar GS, Cengiz SD, Karadağ D, Yılmaz MB. Clinical diagnosis and complications of paratubal cysts: review of the literature and report of uncommon presentations. Arch Gynecol Obstet 2012;285:1563-1569. http://dx.doi.org/10.1007/s00404-012-2304-8

14. Onur MR, Bakal U, Kocakoç E, Tartar T, Kazez A. Cystic abdominal masses in children: pictorial essay. Clinical Imaging 2013;37:18-27. http://dx.doi.org/10.1016/j.clinimag.2012.03.010

15. Liu H, Wang X, Lu D, Liu Z, Shi G. Ovarian masses in children and adolescents in China: analysis of 203 cases. $J$ Ovarian Res 2013;6:47. http://dx.doi.org/10.1186/1757-2215-6-47

16. Singla DK, Kansal R, Bansal I, Thami G, Agrawal N. Case report: laparoscopic management of a giant ovarian cyst. Asian Pac J Health Sci 2014;1:43-46. 